\title{
Family centred care across the life continuum
}

Ingegerd Bergbom RN; BSc, NT, PhD, Professor, Institute of Health and Care Sciences, Sahlgrenska Academy, University of Gothenburg, Gothenburg, Sweden

E-mail: ingegerd.bergbom@gu.se

Key Words: family care intensive care $\quad$ nursing

\section{SUMMARY}

- $\quad$ Staff in intensive care units must be prepared to provide family friendly care.

- Nurses in intensive care units usually do not have any knowledge about patients' family structures and dynamics.

- Close relatives need to watch over the patient and be vigilant.

- Participation and fellowship are important in the care of patients and their families.

- It is suggested that there is much that can be done to improve the intensive care environment to make it more family friendly.

\section{INTRODUCTION}

In intensive and critical care, patients of different ages and different backgrounds and life situations are cared for, and their families and relatives also have different ages and are in different life situations. Thus staff in the intensive care unit (ICU) must be prepared to care for individuals with different needs. Perhaps family centred care (FCC) is most important in intensive care units, compared to other units, because of the occurrences of dramatic and often tragic circumstances? In these situations, the development of family involvement in the care and what is happening to the patient is a great challenge for practitioners.

The concept of FCC is sometimes mentioned as family oriented care or sometimes as family friendly care. However, these concepts are rather unclear and sometimes confusing, which has been noted by several authors (Darbyshire, 1993; Nethercott, 1993). Cunnigham's (1978 p.35) definition of FCC is widely used and is as follows:

"care given to the total family. While the care may be focused on one member, the public health nurse will be aware of the effect of the problem on the whole family and the family's effect on the problem. The focus of care may change from one individual to another. This means that the needs of all family members must be assessed with the aim of health promotion and early case finding."

Cunningham defined the concept in relation to public health nursing, but this definition can also be used in other health care settings such as in ICU. Cunningham points out that if anyone in the family is sick or injured the whole family is affected. The family also affects the actual problem and the patient. Thus, the nurse must be aware of, not only the patient's needs but also of the dynamics and needs within the family.
The concept of FCC was first introduced in paediatric care in the mid 1950s. It was implemented by many hospitals during late 1970s. Barnhill's (1979) theory of the healthy family cycle was important in this development. This resulted in a paradigm shift in many countries. In paediatric units especially, parents were wanted and included in the care of the sick child, and not excluded from participation in treatment, doctors' rounds and examinations. Another important occurrence was the British Platt report (Central Health Services Council, 1959). This report was mainly based on Bowlby's studies $(1951 ; 1965 ; 1970)$ which were important in the improvement of care of children in hospitals (Alsop-Shields \& Mohay, 2001). This knowledge resulted in a more child and family friendly practice, in which parents were encouraged to participate in care, and to assist in the recovery process. This paradigm shift is still ongoing and most nurses have the opinion that it is good for the child to have the parents' presence because that they can help to care for the child during the hospital stay.

Based on Barnhill's (1979) theory, Hall et al. (1994), Hall (2005b) and Wilson et al. (1993) suggests the words "experiences" and "dynamics" when we talk about the relationships in the family, between family members and nurses/professionals and between professionals or within a group of professionals. Thus, the dynamic between the patient and the nurses/professionals also should be included in FCC. I will first discuss issues that concern the family and then some concepts of caring which could be seen important in caring of patients and their families.

\section{Family}

What do we mean by a family? The word family often refers to generic relationships and blood relationships. The word family comes from the Latin word familia and from the words famulus which is servant, and famula which is servant or maid. Originally it meant serving or attendance and thereafter dependent. Today, many use the word family in the meaning of relatives and generic lines of both parents and their children. But today the Italian word famiglia means the servants and staff, and the word famiglio is synonymous with domestico (servants) (Bergman, 2003). According to this, family can include persons with no blood or generic relationships.

The structure of families and their relationships is complicated The family can consist of parents and children, often known as the nuclear family. But we can also refer to family relationships in which the wife's or husband's or partner's brothers and sisters, father and mother are considered as their families. Other constructions of families in many other countries include, for example, husband and wife having children from previous marriages. These children 
may have several grandmothers and grandfathers and the wife and husband several mothers and fathers in law. Children may have different kinds of siblings such as half-brothers and half-sisters or siblings without any generic relation ties. This kind of family structure is often called the extended family.

The third type of family is also sometimes called significant others, close/important others or friends, and is somewhat different. In this type of family the dependency of each other is built upon closeness and the trustful relationship. The relationship is characterised by intimacy but it could be someone who takes care of practical things and there exists a mutual confidence. In the two first types of family it is the structure and legal relationships which define what a family is, but in the third, it is the importance or quality of the relationship which defines the family.

The number of one-person households is increasing in the western world (Statistiska Centralbyrån, 2000). Many have chosen to live without any family or relationships to relatives. Others have not chosen to live alone, but circumstances have developed in that way. Some have a family, but do not want to have any relationships or contacts perhaps because of previous conflicts, or difficult and complicated personal relationships.

So, when we talk about FCC, we must first clarify what we mean by this.

\section{Critical illness or injury and the dynamics within families}

Critical illness or severe injuries in any family can trigger a process which can reveal conflicts embedded and suppressed during many years, and the whole structure of the family can be threatened. But the dynamics within the family may also be strengthened and loyalty and support can unify the family. Relationships between partners can become deeper and closer (Maddox et al., 2001). When a family member becomes critically ill or is severely injured, the routines in the family will change, and this can disrupt their normal existence and usual patterns of life. Relatives are also faced with an existential uncertainty (Bahnson, 1987) and the very stressful factor of the awareness of the patient's possible death (Caplin \& Sexton, 1988; Artrinian, 1989; 1991).

In paediatric and neonatal intensive care units, for example, FFC is created around the sick child (see for example Hall, 1999; 2001; 2007). The staff know who the child's parents are, and it is easy to find out if the child has any siblings and if there are any grandparents. In adult ICUs, nurses often do not have any knowledge about their patients' relationships, family structure or the dynamics within the family or their relatives. Therefore nursing care is usually planned and conducted based on the nurses' assessment of what is best for the patient. Nursing care activities aim for a positive outcome for the patient, not only the patient's survival, but also the patient's wellbeing in the long-term.

We can conclude that it is extremely difficult to define and understand the dynamics within patients' families. Sometimes the nurses may have an intuitive feeling that something is wrong, that the patient's reactions or responses to the visitor may reflect the quality of the relationship. For example, the patient becomes either worried or calm and relaxed. But it is always difficult to interpret patients' reactions. For example patients may start to cry when a family member visits. We can interpret these visits as evoking unpleasant feelings or conversely, making the patient feel confident and relaxed, daring to show all his or her feelings of fear, sorrow and despair.

\section{Interactions between the family and the nurse}

It has been discussed that there are many and varied attitudes among nurses to FCC and that nurses' knowledge of FCC is not always put into practice. Others state the opinion that nurses do not have an adequate knowledge of family theories and their role in this.

Even if all nurses agree about the importance of FCC for patients, family members' and the nurses' health and well-being there still remain some difficulties and problems. For example, few ICUs have guidelines for the care of children who accompany adults when visiting ICU patients (Knutsson et al., 2004; Vint, 2005). It is important to emphasise that children are also family members. Restricting or not restricting children to visit has been discussed but no studies from the children's perspective have been conducted.

There are some problems and questions concerning the dynamics between professionals and family members. These are:

\section{- $\quad$ expectations of nurses about the family, and vice versa; \\ - a possible conflict or a collaboration and interaction; and \\ - is there evidence that FCC is improving child, patient and/or family health and well-being?}

\section{Nurses' expectations about family members and vice versa}

There are different interactions and relationships in the dynamics of the nurse-family. Some are built upon trust and confidence, but others are caused by mistrust and suspicion. Cultural factors and language difficulties also have an impact on the nurses' and family members' perceptions and their understanding of the situation. But there are also misunderstandings because of preconceptions. Nurses' expectations about family members' involvement in the care process must be clarified and fully understood and family members' expectations about the role of the nurse must also be defined. This concerns visiting policies, presence in the room, asking questions, how to behave in relation to other patients in the room, the number of visitors allowed, involvement in any nursing care and family expectations of nurses' behaviour, competency and skills.

\section{Conflicts or collaboration and positive interactions}

In paediatric intensive care, power struggle about the ownership of the child/patient (Evans, 1994; Shields et al., 2003) and the parental role during the child's stay in hospital (Moynihan et al., 1995; Cohen, 1995; Simons et al., 2001) has been described.

Söderbäck (1999) described three different styles the nurses had in their relationship or interaction with parents to a sick child. These were: the demanding style, the eliciting style, the collaborating style and the assumptive style. These styles incorporate paternalism to cooperation.

Simons et al. (2001) outlined the FCC as a continuum from parentled care to nurse-led care and a partnership. In nurse-led care the parents have a minimum of involvement in the care and in parentled they have a maximum of involvement. In the partnership nurse and parents have equal status. According to Espezel and Canams' (2003) study the parents wanted access to reliable data and sharing the care of the children and they wanted consistency of staff.

Similar findings are described in research of relatives' and family members' needs and wishes in adult ICU. For example, relatives wanted continuity in nursing care and consistency of nurses because then it was easier to build up a trustful relationship with the nursing staff (Hall, 2007).

Other possible conflicts can appear when professionals and family members interpret the patient's clinical signs and reactions differently. Hall (1999) found, for example, that intuitive knowing among mothers showed that they could identify any deteriorating condition of their child before the professionals, which sometimes created conflicts between mothers and nurses. When the parents' observations were not taken seriously, they felt that the professionals were ignorant. Similar experiences have been seen in adult ICU. Callery (1997a) explained this as private and public knowledge, and most nurses 
agree that both these types of knowledge are needed in patient care. When nurses and the family work together, the interaction takes place in the form of communication and the exchange of knowledge.

Is there evidence that FCC is improving child, patient and/or family health and well-being?

This question can be developed into additional three questions:

1. Does family centred care improve family members' health and well-being?

There are several studies and articles that discuss the advantages and disadvantages of FCC in relation to patients' and family members' health and well-being, but more research is needed. Nicholson et al. (1993) showed that if a child was allowed to visit their relative, and if they received information before entering the patient's room, their stress decreased. Since the 1980s it has been discussed whether or not young children should be allowed to visit patients cared for in ICU (Goodall, 1982; Lewandowski, 1992; Nicholson et al., 1993). Leske (1986) and Burr (1998) studied the needs of relatives in the critical care context. But knowledge about the effect of FCC on relatives' health and well-being in a short term as well as long-term perspective is needed.

2. Do family members and their bedside presence have any impact on the ICU patient's health, recovery, well-being and survival?

Several studies have shown that persons close to the patient are important in the nursing care of the patient (West, 1975; Gardner \& Stewart, 1978). Molter's (1979) research was important for the development of FCC in ICU. Molter concluded that any crises and conflicts between the patient and patient's family, which were unresolved, could affect the development and the deterioration of the patient's illness and medical condition. Further research was conducted, and for example, Leske and Molter's (1983) instrument - the Critical Care Family Needs Inventory - was developed. It is obvious that meeting the needs of family members has a positive effect on the patient's health condition (Burr, 2002).

In an interview study of patients' experiences regarding relatives/ close persons including young children visiting them during their stay in the ICU, patients reported that the family members' presence made them feel safe and secure, and that they knew they were loved and that these persons wished that they should survive (Bergbom \& Askwall, 2000). The family members' presence was very important for their feelings of security. They could relax when their relative could see what was happening to them. They also stated that these close persons were more important than the nurses (Bergbom \& Askwall, 2000), and that the quality of the relationship was vital. Thus, the family members or close persons had an impact on their "survival". It was also important for the patient's well-being to feel love for the family members who visited or stayed with them because this made them feel strong and helped them to overcome their exhaustion. Close persons and family members are thus able to support, and console patients and help them to feel calm and relaxed (Granberg et al., 1999; Bergbom \& Askwall, 2000). Caplan's (1976) research shows that these supportive systems have a positive health effect. Other studies also support this (Simpson, 1991; Hupcey \& Zimmerman, 2000; Madox et al., 2001). Significant others, or their nearest relative, could anchor the patient in their normal, real life, and help them to survive. This was confirmed in another study where patients reported that persons who they trusted or had a good relationship with, could, by their presence, prevent or stop negative experiences such as unreal experiences, nightmares and delusional and confusing occurrences (Granberg et al., 1999). However, patients also said that they did not want any visitors who they did not like, or felt uncomfortable with. They did not wish to have any visitors who they were forced to be polite to. They did not have the strength for this.
Armstrong Lazure (1997) studied patients' reactions such as blood pressure and heart rate during their relatives' stay and visits in the $\mathrm{ICU}$, and compared the findings with a control group. They found that diastolic blood pressure and heart rate decreased during visits in comparison with the control group, but Schulte et al. (1993) did not found any decrease in heart rate. Many nurses have the opinion that patients who have no visitors while they are cared for in the ICU are more likely to die, but Eriksson and Bergbom (2007) found that patients' mortality was not affected by having or not having any visiting relatives during the ICU stay. Thus, there are some conflicting results. However, patients cared for without any restricted visiting hours had significantly lower heart rates following visits, than patients in ICUs where the visiting hours were restricted (Schulte et al., 1993). So, the presence of family members would appear to have a beneficial caring effect but more research is needed to support this.

3. Can any differences be seen between patients and family members' health and well-being when family centred care is implemented, compared to when it is not utilised?

I will attempt to answer this question by referring to some concepts and phenomena, which I think are of importance in caring. These concepts are participation, knowing, vigilance, and fellowship or mutuality; and they are interlaced.

\section{Participation}

The word participation means the state of participating or sharing in common with others. Share means to have something common, to see, and to take part in. To participate in is to take part in, to enjoy, take responsibility for and contribute to. Synonyms are: involved in, interested in, engaged in, initiated, to be a partner and participator, being jointly responsible and being a contributor. The essence of participation is summarised in the following phenomena: insight, understanding, reflection, and sympathy. Participation and sharing is related to knowing, which been described by Eriksson (1987), Kirkevold (1996) and Hall (2005a; 2005b).

If a person is not feeling well or is suffering, and when this suffering cannot be shared with another person, it is impossible to participate and share other experiences such as work and life-stories. When we cannot or are not able to share we have to take into consideration the risk for disintegration (Fromm, 1962; Eriksson, 1987). In conclusion, participation is a presence which leads to fellowship. The experience of a concrete or abstract presence of another person or significant other can mean experiences of fellowship and mutuality and to be a part of something.

Participation, sharing and knowing is important in family centred caring. By knowing, the family members become participants and they share knowledge about the patients' condition. Research has shown that it is vital for family members to know what is going on, to be continuously informed in an understandable language and to have an overview of the situation (Burr, 1998; Hall, 2005a). It is also important for the family to know from whom they can receive information, and who are responsible for the patient during the nurses' different shifts. Knowing helps family members to cope and care for the patient and participation includes mutual exchange of information between family and nurses. Thus knowing is interwoven in the dynamics around the patient and is essential for the whole family's health to know what is happening to the patient.

Knowing is also a way to cope with uncertainty, despair and fear of losing the patient. Family members want to have a preparedness of knowing to be able to handle the situation and to be prepared should the worst happen (see Burr, 1996). Their pain, sorrow and worries are soothed or alleviated by being knowledgeable and vigilant. Distrust of nursing care occurs when there is ignorance among the staff, 
or if they are given conflicting information. This creates insecurity, feelings of isolation and distrust and nurses are not seen as being knowledgeable (Hall, 2005a; 2005b).

Hall (2001) found in an interview study with nurses that knowing, for the nurse, was to know what to do and to have an overview of the situation, and to have some kind of control. Otherwise, they felt uncertain and vulnerable. This was important for good nursing care of the patient and the family and for the well-being of the nurses. Participation also meant sharing the work and the responsibilities of the team and with other nurses involved in the care of the patient.

Very few studies have focused on families' and the patients' experiences of participation and sharing of "knowledge" about the patients' condition and what has happened during the stay in the ICU. However, some studies about the effects of diaries kept for patients and their relatives have been published and today many ICUs keep diaries for their patients and families. We need, for example, to find out what it means for the patient and the family dynamics when family members are "knowing", when the patient does not know or has been able to share what has happened in relation to his or her medical condition. This is especially important when patients have been unconscious or have no memories from their ICU period.

In an interview study by Granberg et al. (1998) one patient reported that she was very disappointed and felt isolated because her husband knew more about her condition and experiences that had happened during her stay in the ICU than herself. She felt unknowing, isolated and separated and not able to share the "knowing" her husband had. This created suspicion in their relationship: he knew something about her and her life that she did not.

\section{To watch over the patient and be vigilant}

Several researchers (Burr, 1998; Frid et al., 2001; Hall, 2005a; Fridh \& Bergbom, 2006) have described the importance for the family to watch over the critical ill or injured patient, or they discuss or describe vigilance. The word vigilance comes from the Latin word vigilis which is to be awake and the word vegere which means to cheer up. The Latin word vigilo means to keep awake, to be alert and watchful, to keep the eyes open, and to care. The adjective vigilantia means watchfulness and consideration. Vigil is the act of keeping awake and implies a devotional watching. Vigilance is the state of quality of being vigilant. The discrimination paradigm in Swedish shows that there are six groups of synonyms which describe the content of vigilance. These are: to be awake or stay up, to watch, to supervise or see to, to look after to protect and to have charge of. In the study by Fridh and Bergbom (2006) it is concluded that "to watch over means to be present at somebody's side with attention, with the purpose to protect the person from danger and to assist and help when the person is ill or dying. The vigilance can take place both in days and nights, being carried out by carers (nurses) or close persons to the sick or dying. The vigilance contains an emotional engagement where any personal needs are put aside in order to carry out caring and worrying for the sick or dying person."

To be awake means to be alert and curious and to be attentive, but also means to be sleepless. The watching person sacrifices something for the patient. To watch over means to be careful, to guard and look after the patient's interests, to assist and to ensure that nothing bad can occur. To supervise or oversee means to keep a watching eye on what is happening. To look after, means to wait, and to nurse and to give care, and be there for the other person. To protect, means to defend, support and ward off evil and to guard the other person. Finally, to have charge over, means to inspect and control and supervise. It would seem that the concept of vigil and vigilance is a very important act and phenomenon in the caring process.

The importance for family members to be present in the patient's room, to be close, to touch and be able to talk to the patient is well known by most ICU nurses. It is seen as important by relatives to be allowed to touch the patient, and sometimes to participate in practical nursing procedures because this could help the family members to handle their feelings of helplessness. Just to be present, and be there, is felt by family members to do something to help the patient. Generally, this type of support is accepted by nurses. But they can also experience the family members' presence as difficult, when they perform different nursing care actions. The family members constant presence is often accepted when the patient's condition is very critical and severe, or when the patient is expected to die or is dying.

In research by Hall (2005a) vigilance can alleviate sorrow and despair and decrease family members' suffering. To wait, to be attentive and to hope for positive signs of recovery may strengthen the family members' support and feelings of being close to the patient. Waiting and realising the deterioration in the patient's condition may encourage the unity of the family and the care of each other within the family.

Based on this knowledge, we must continue with research that takes all aspects of vigilance into consideration, when studying patients' experiences of vigilance and the long-term effects on family members' health.

\section{Fellowship}

Fellowship or community comes from the Latin word com-munis, from moin which means exchange and from munis which means duty, obligations and mutuality. Ship comes from creation.

Fellowship can, from a caring perspective, be described as follows: the condition of being a fellow or associate, mutual association, equal and friendly terms, companionship, partnership, and joint interest. The condition for fellowship or mutuality is some kind of agreement, by being human beings, which includes suffering and joy, as well as sorrow and despair, through sharing experiences and memories and through the language (Cöster, 2001). The concept of equal value is important, and is the basis for the experience of fellowship and mutuality. This means that there is a possibility to share joy and sorrow and that this sharing allows new possibilities in the creation of something new. Mutuality implies an exchange, but also a dependency. Fellowship and mutuality create and is a basis for openness, creativity and the possibility to re-examine present thinking, and can lead to new approaches and thoughts.

Hall (2005a; 2005b) uses the word mutuality based on Barnhill's (1979) framework of healthy family systems. According to Barnhill, mutuality refers to closeness and intimacy, and is a central concept in a healthy family circle. The opposite is isolation, in which the person is not included in the communion, and there is a risk of feelings of alienation. In the dictionary, mutuality is defined as those relationships, interests, likes and dislikes that are equally shared (Longman, 1992), but Hall (2005a; 2005b) describes mutuality as to care and be open and, referring to Benner and Wrubel (1989), to want to be of help to each other, to need and accept help from each other, and to treat each other with respect and dignity. In this meaning, the concept is close connected to togetherness.

A study by Aittamäki et al. (1999) found that relatives and spouses were prepared to sacrifice much for the fellowship with the patient, but that they experienced a struggle between responsibility and guilt. This responsibility also created a fellowship which included joy, closeness, sharing of experiences and possibilities for the family to develop and care for each other. This fellowship and mutuality can continue to grow even after the patient's death. However, the responsibility can also create loneliness if other family members do not take their share of the responsibility. Because of the patient's condition, the mutual relationship can easily become one-sided or unilateral. The patient could exclude others, which is common when 
the patient feels exhausted, frightened, and that death is near. Nurses' actions and attitudes are very important in these situations. Nurses, by their actions, can destabilise a growing fellowship, for example, by giving the patient more sedation or recommending the spouse should leave. The meaning of responsibility lies in an actual presence, which means that the family member must be present at the bedside because this is how fellowship works and is made possible.

Fellowship within families having a sick child is also important. Some parents of a sick child find support and care from their own parents, that is, the child's grandparents, and that they can share and help each other to endure and survive critical moments (Callery, 1997b). Mutuality could help parents and grandparents not to feel isolated or not part of the family or being a stranger (Hall, 2002; 2005a). Several researchers and authors have found that children of adult patients cared for in ICU should be involved, and not protected from what is happening, when a family member is critically ill or injured. Fellowship makes children feel important, and not isolated. The children will then have the opportunity to share sorrows and hopes with the adults in the family.

Wilson et al. (1993) found that the dynamic between the family and professionals developed and was a process from feelings of isolation towards feelings of partnership. Parents of sick children appreciated professionals who could communicate with them, and inform and also perhaps make a joke and talk with them about everyday matters and the world outside the hospital and things that were of mutual interest. This gave the impression that the professionals were pleasant and kind, and made their anxiety easier to endure because they could share something with the family (Hall, 2005b). Fellowship and mutuality imply sharing and this contribute to possibilities for family members to relax and have a pause from their worries and anxieties. Fenwick et al. (2001) supports the importance of this social interaction, and strategy through which relationships are initiated, maintained and enhanced. Similar findings have been described in studies from adult ICU. We found, for example, that fellowship was essential when family members were awaiting information about the patient's condition. If the patient had been declared brain stem dead, the nurses shared the family's worries, despair and sorrow. If no mutuality existed the nurses were described as "robots with chilly eyes" (Frid et al., 2001).

Fellowship between professionals refers to effective teamwork, cooperation and sharing of responsibility, colleagues who are helpful, and who they could talk to, and share their feelings, and experiences with (see for example, Hall, 2001). Through generations, or internally between professionals, fellowship and mutuality seems to create a sense of togetherness and community, as human beings, being members of a family or members of a team. This helps to combat any feelings of loneliness and isolation. Feelings of isolation and alienation could result in long-lasting and unpleasant memories.

According to Barnhill (1979), mutuality contributes both to family and professional health and well-being.

\section{The environmental context - is it truly caring?}

The ICU environment and the treatment given to patients are characterised by the use of high technology machinery and devices. The ICU department was created with the purpose of saving life, and to enable the staff to work and use the equipment efficiently in the treatment of patients. Many ICUs have no or very few single rooms for patients and often they have not been designed to respond to patients' and families' needs for privacy and integrity. Research has shown that the ICU environment is often experienced as stressful and frightening, by both patients and their families. Fontaine et al. (2001) found that the ICU environment is a contributory factor in the development of medical complications and it also increases patients' experiences of stress. The equipment can make it difficult, and sometimes impossible, for family members to come close to the patient. Eye contact between the patient and family members is sometimes impossible. Lack of privacy in two-bed rooms and the limited space around the bed are obstacles for good nursing care. The lack of rooms in ICUs for family members for rest and private conversations also shows that the environment is not family friendly, and thus is not conducive to FCC. Such conditions are a reality in many ICUs worldwide, and many ICUs do not have an acceptable level of nursing care regarding dying patients and their families.

A caring culture not only means that the physical environment should support and facilitate caring. It also means that the relations, will, mood, and atmosphere between the professionals or the team members in the ICU are of the highest quality. The atmosphere should allow for the caring of patients and their families, and to acknowledge care of the professionals by their participation, sharing, knowing, fellowship, mutuality and vigilance.

The atmosphere of the quality of relations within the team affects the patient, as well as family members visiting the patient. Several researchers and nursing theorists (for example, Eriksson, 1987; Benner et al., 1996) have emphasised the importance of a good and developing emotional atmosphere for patients', family members' and professionals' health and well-being. A caring culture will also make the unit a good place to work for the professionals.

In an interview study of about 300 patients (Bergbom Engberg, 1989), it was found that patients were aware of how their family members were met and treated by professionals. They could also recall and describe their experiences of the atmosphere in the room. For example, patients said that they could not stand arguments or unfriendly talk between the team members. It made them feel insecure and frightened. Other patients reported that an unfriendly tone or a negative attitude towards the family by the team members created feelings of mistrust and insecurity, but a friendly, positive and caring attitude to visiting family members created security, trust, hope and joy (Hall, 2007). In another study, patients said that their family members were welcomed by the nurses and that there was a warm and close atmosphere (Bergbom \& Askwall, 2000).

FCC does not finish when the patient is discharged from the ICU. During patients' recovery at home, thoughts about what has happened and adverse memories may evoke unpleasant feelings and may delay recovery, health and well-being. Patients and family members are not always in step. The patient may still not feel well, while family members can see that the patient is no longer in a critical condition and therefore should do something, and not just sit and think. In a follow-up study, we found that many patients' relationships with spouses, family members and friends changed after the critical care period. Some rejected their families, some deepened their fellowship and some tried to hide their feelings and experiences, and adopted an acceptable and expected social behaviour in fear of loosing their family and relationships.

A great deal of research has been already been conducted in this field, but more research is still needed, and we must develop further theories concerning FCC in both intensive nursing care and caring science.

\section{NOTE}

This article is based upon a plenary presentation given at The 2nd Congress of the European federation of Critical Care Nursing association, 11 November 2005, Amsterdam, The Netherlands. 


\section{REFERENCES}

Aittamäki M, Lindström UÅ, Bondas-Salonen T (1999). Gemenskapens nya skepnad Anhörigvårdares upplevelser av att vårda svårt sjuka patienter $\mathrm{i}$ hemmet. [The new shape of fellowship: relatives as carers and their experiences to care for severely ill patients in the home] Åbo Akademi, Institutionen för vårdvetenskap Rapporter 1:1999.

Alsop-Shields L, Mohay H (2001). John Bowlby and James Robertson: theorists, scientists and crusaders for improvement in the care of children in hospital. Journal of Advanced Nursing 35 (1), 50-58.

Armstrong Lazure LL (1997). Strategies to increase patient control of visiting. Dimensions of Critical Care Nursing 16 (1), 11-19.

Artinian NT (1989). Family members' perception of a cardiac surgery event. Focus on Critical Care 16 (4), 301-308.

Artinian NT (1991). Stress experience of spouses of patients having a coronary artery bypass during hospitalisation and 6 weeks after discharge. Heart \& Lung 20 (1), 52-59.

Bahnson CB (1987). The impact of life-threatening illness on the family and the impact of the family on illness: an overview. In: Families and Life-threatening Illness, edited by M Leahey \& LM Wright. Pennsylvania, Springhouse.

Barnhill LR (1979). Healthy family systems. The Family Coordinator January, 94-100.

Benner P, Wrubel J (1989). The primacy of caring. Stress and Coping in Health and IIIness. Menlo Park, CA, Addison-Wesley Publishing Company.

Benner P, Tanner CA, Chesla CA (1996). Expertise in nursing practice. Caring, clinical judgement, and ethics. New York, Springer Publishing.

Bergbom Engberg I (1989). Patients' experiences of respirator treatment. A retrospective study of the influence of medical and nursing care factors on recall, experience of discomforts and feelings of security or insecurity. Doctoral dissertation, University of Gothenburg.

Bergbom I, Askwall A (2000). The nearest and dearest - a lifeline for ICU patients. Intensive and Critical Care Nursing 16 (6), 384395 .

Bergman G (2003). Ord med historia. Etymologisk ordbok. [Words with history. Etymological Dictionary]. Stockhom, Bokförlaget Prisma.

Bowlby J (1951). Maternal Care and Mental heatlh. Geneva, World Health Organization.

Bowlby J (1965). Child care and the growth of love. Harmondsworth, Penguin Books.

Bowlby J (1970). Attachment and loss. London, The Hogarth Press and the Institute of Psycho-analysis.

Burr G (1996). An analysis of the needs and experiences of families of critically ill patients; the perspectives of family members and ICU nurses. Department of Clinical Nursing, Faculty of Nursing, University of Sydney, Australia (Reaktioner och relationer i intensivvård - närståendes behov och sjuksköterskors kännedom om behoven Lund, Studentlitteratur 2001).

Burr G (1998). Contextualising critical care family needs through triangulation: an Australian study. Intensive and Critical Care Nursing 14 (4), 161-169.

Burr G (2002). "Giving each other energy" - harnessing valuable resources for clinical practice. Intensive and Critical Care Nursing 18 (1), 2-12.
Callery P (1997a). Maternal knowledge and professional knowledge: co-operation and conflict in the care of sick children. International Journal of Nursing Studies 34 (1), $27-34$.

Callery P (1997b). Caring for parents of hopitalised children: a hidden area of nursing work. Journal of Advanced Nursing 26 (5), 992-998.

Caplan G (1976). The family as a support system. In: Family Stress, Coping, and Social Support, edited by HI McCubbin, AE Cauble \& JM Paterson 1982, Springfield Illinois Charles Thomas.

Caplin MS, Sexton DL (1988). Stresses experienced by spouses of patients in coronary care unit with myocardial infarction. Focus on Critical Care 15 (5), 31-40.

Central Health Services Council (1959). The Welfare of Children in Hospital: Report of a committee of the Central Health Services Council (The Platt Report). London, HMSO.

Cohen WI (1995). Family-oriented pediatric care - taking the next step. Pediatric Clinics of North America 42 (1), 11-19.

Cunningham R (1978). Family centred care. More than a cliché. The Canadian Nurse February, 34-37.

Cöster H (2001). Människa bland människor [Human among human beings]. Karlstad University Studies 2001: 12.

Darbyshire P (1993). Parents, nurses and paediatric nursing: a critical review. Journal of Advanced Nursing 18 (11), 1670-1680.

Eriksson K (1987). Vårdandets idé. [The Idea of Caring] Stockholm: Almqvist \& Wiksell.

Eriksson T, Bergbom I (2007). Visits to intensive care unit patients - frequency, duration and impact on outcome. Nursing in Critical Care 12 (1), 20-26.

Evans MA (1994). An investigation into the feasibility of parental participation in the nursing care of their children. Journal of Advanced Nursing 20 (3), 477-482.

Espezel HJE, Canam CJ (2003). Parent-nurse interactions: care of hospitalised children. Journal of Advanced Nursing 44 (1), 34-41.

Fenwick J, Barcley L, Schmied V (2001). 'Chatting': an important clinical tool in facilitating mothering in neonatal nurseries. Journal of Advanced Nursing 33 (5), 583-593.

Fontaine D, Briggs L, Pope-Smith B (2001). Designing humanistic critical care environments. Critical Care Nursing Quarterly, 24 (3), 21-34.

Frid I, Bergbom I, Haljamäe H (2001). No going back: Narratives by close relatives of the braindead patient. Intensive and Critical Care Nursing 17 (5), 263-278.

Fridh I, Bergbom I (2006). Att vaka - en begreppsanalytisk studie [Vigil - concept analytic study]. Vård i Norden 1, 4-8

Fromm E (1962). Själsharmoni och moral. [Harmony of the soul and moral]. Solna, Tryckindustri.

Gardner D, Stewart N (1978). Staff involvement with families of patients in critical-care units. Heart \& Lung 7 (1), 105-110

Goodall J (1982). Children under 14 years are urged to visit these wards. Nursing Times 78, 1366-1377.

Granberg A, Bergbom Engberg I, Lundberg D (1998). Patients' experiences of being critically ill or severely injured and cared for at an intensive care unit in relation to the ICU syndrome. Part 1. Intensive and Critical Care Nursing 14 (6), 294-307.

Granberg A, Bergbom Engberg I, Lundberg D (1999). Acute confusion and unreal experiences in intensive care patients in relation to the ICU syndrome. Part II. Intensive and Critical Care Nursing 15 (1), 19-33. 
Hall EOC, Wulff T, White MA, Wilson ME (1994). Family dynamics during the third trimester of pregnancy in Denmark. International Journal of Nursing Studies 31 (1), 87-95.

Hall EOC (1999). Fra afdeling til afdeling. En fenomenologisk undersögelse af indholdet i sygeplejen ved et lille barns overflytning til eller fra intensive afdeling.[From unit to unit. A phenomenological study of the nursing when a small child is transferred to and from intensive care unit]. PhD afhandling I sygepleje. Århus, Det Sundhedsvidenskabelige Fakultet, Aarhus Universitet.

Hall EOC (2001). From unit to unit. Danish nurses' experiences of transfer of a small child to and from an intensive care unit. Intensive and Critical Care Nursing 17 (4), 196-205.

Hall EOC (2002). Grandparenting - a matter of love and care. A review of the literature 1990-2000. International Journal of Human Caring 6 (3), 55-62.

Hall EOC (2005a). Being in an alien world: Danish parents' lived experiences when a small or newborn child is critically ill. Scandianvian Journal of Caring Sciences 19 (3), 179-185.

Hall EOC (2005b). Danish parents' experiences when their newborn or critically ill small child is transferred to the PICU - a qualitative study. Nursing in Critical Care 10 (2), 90-97.

Hall EOC (2007). When a newborn or small child is critically ill. Nurses', parents' and grandparents' experiences and dynamics in family-centred care. MD-thesis, Faculty of Health Sciences, University of Aarhus, Denmark.

Hupcey J, Zimmerman H (2000). The need to know: experiences of critically ill patients. American Journal of Critical Care 9, 192-198.

Kirkevold M (1996). Vitenskap for praksis? [Science for praxis] Olso, Ad Notam Gyldendal.

Knutsson S, Otterberg CL, Bergbom I (2004). Visits of children to patients being cared for in adult ICUs: policies, guidelines and recommendations. Intensive and Critical Care Nursing 20 (5), 264-274.

Leske JS (1986). Needs of relatives of critically ill patients: a follow up. Heart \& Lung 15 (2), 189-193.

Lewandowski LA (1992). Needs of children during the critically illness of a parent or sibling. Critical Care Nursing 4 (4), 573-85.

Longman (1992). Dictionary of English Language and Culture. Essex, Longman Group UK Limited.
Maddox M, Dunn SV, Pretty LE (2001). Psychosocial recovery following ICU:experiences and influences upon discharge to the community. Intensive and Critical Care Nursing 17 (1), 6-15.

Molter NC (1979). Needs of relatives of critically ill patients. A descriptive study. Heart \& Lung 8 (2), 332-339.

Moynihan P, Naclerio L, Kiley K (1995). Parent participation. Nusing Clinics of North America 30 (2), 231-241.

Nethercott S (1993). A concept for all the family. Family centred care: a concept analysis. Professional Nurse 8 (12), 794-797.

Nicholson AC, Titler M, Montgomery LA, Kleiber C, Caraft MJ, Halm M, Buckwater K, Johnson S (1993). Effects of child visitation in adult critical care units: A pilot study. Heart \& Lung 22 (1), 36-45.

Schulte DA, Burell DC, Geuldner SH, Bramlett MH, Fuszard B, Stone SK, Dudley WN (1993). Pilot study of the relationship between heart rate and ectopy and unrestricted vs restricted visiting hours in the coronary care unit. American Journal of Critical Care 2 (2), 134-136.

Shields L, Kristensen-Hallström I, Kristijánsdóttir G, Hunter J (2003). Who owns the child in hospital? A preliminary discussion. Journal of Advanced Nursing 41 (3), 213-222

Simons J, Franck L, Roberson E (2001). Parents' involvement in children's pain care: views of parents and nurses. Journal of Advanced Nursing 36 (4), 591-599.

Simpson T (1991). Critical care patients' perceptions of visits. Heart \& Lung 20 (6), 681-688.

Söderbäck (1999). Encountering parents. Professional action styles among nurses in pediatric care. Dissertation. Göteborg, Göteborg Studies in Educational Sciences 139.

Statistiska Centralbyrån [Statistics in Sweden] (2000). Statistical Yearbook of Sweden. Stockholm: Statistiska Centralbyrån (Statistics Sweden).

Vint PE (2005). An exploration of the support available to children who may visit a critically adult in ITU. Intensive and Critical Care Nursing 21 (3), 149-159.

West ND (1975). Stresses associated with ICU's effect: patients, families, staff. Hospitals 49, 62.

Wilson ME, Hall EOC, White MA (1993). Family dynamics and infant temperament in Danish families. Scandinavian Journal of Caring Sciences 8 (1), 9-15. 